\title{
A APLICAÇÃO DE TERAPIAS ALTERNATIVAS NO CONTROLE DA ANSIEDADE EM PROFISSIONAIS ATUANTES EM UM GRUPO PELA UNIDADE INFANTO- JUVENIL DE ONCO-HEMATOLOGIA
}

THE APPLICATION OF ALTERNATIVE THERAPIES IN CONTROLLING ANXIETY IN WORKING PROFESSIONALS IN A GROUP BY THE CHILDREN'S ONCOHEMATOLOGY

Juliana Folchini Nunes ${ }^{1}$, Lidiane Gonçalves Ramos², Izabel Scarabelot Medeiros ${ }^{4}$, Susane Raquel Périco Pavei ${ }^{5}$, Maria Tereza Soratto ${ }^{3}$

${ }^{1}$ Enfermeira. UNESC - Universidade do Extremo Sul de Santa Catarinense. Email: july_folchini@hotmail.com

${ }^{2}$ Enfermeira. UNESC - Universidade do Extremo Sul de Santa Catarinense. Email: lidianeramos.b@hotmail.com

${ }^{3}$ Enfermeira. Mestre em Educação. Professora do Curso de Enfermagem - UNESC Universidade do Extremo Sul de Santa Catarina - Criciúma - SC - Brasil. Email: ism@unesc.net.

${ }^{4}$ Enfermeira. Mestre em Ciências da Saúde. Professora do Curso de Enfermagem UNESC - Universidade do Extremo Sul de Santa Catarina - Criciúma - SC - Brasil. Email: susaneperico@unesc.net ${ }^{5}$ Enfermeira. Mestre em Educação. Professora do Curso de Enfermagem - UNESC Universidade do Extremo Sul de Santa Catarina - Criciúma - SC - Brasil. Email: guiga@unesc.net

\section{Endereço para correspondência:}

Maria Tereza Soratto. Departamento de Enfermagem - Unidade Acadêmica da Saúde - UNASAU - UNESC. Av. Universitária, 1105. Criciúma - SC - Bairro Universitário. CEP - 88806-000. Email: guiga@unesc.net. 


\section{RESUMO}

Estudo com objetivo de identificar a contribuição proporcionada pela aplicação de terapias alternativas no controle da ansiedade em profissionais atuantes em um grupo pela unidade infanto-juvenil de onco-hematologia, de um município do Extremo Sul Catarinense. Pesquisa de abordagem quali-quantitativa, descritiva, exploratória e de campo. O estudo foi desenvolvido com 09 profissionais. Aplicou-se a Escala de Avaliação de Ansiedade de Hamilton na equipe multiprofissional, as terapias alternativas e a entrevista semiestruturada. A análise dos dados qualitativos foi realizada a partir da análise de conteúdo. $\mathrm{Na}$ fase de análise de dados quantitativos da Escala de Avaliação de Ansiedade de Hamilton, as informações foram quantificadas através do Microsoft Office Excel e apresentados por meio de análise quantitativa. O resultado da Escala de Avaliação de Ansiedade de Hamilton indicou que todos os profissionais apresentaram ansiedade, sendo $44,44 \%$ nível leve; 33,33\% nível moderado e 22,22\% nível severo ou intenso. Após a aplicação das terapias alternativas, $28,57 \%$ dos profissionais que apresentaram ansiedade moderada e $28,57 \%$ com ansiedade intensa migraram para ansiedade leve; totalizando 57,14\% com diminuição expressiva do nível de ansiedade. Considera-se a eficácia significativa da utilização das terapias alternativas para o controle da ansiedade dos profissionais e sugere-se a continuidade do cuidado do cuidador como forma de melhorar a qualidade de vida no trabalho.

Descritor: Ansiedade; Qualidade de vida; Organização Não Governamental; Institutos de Câncer; Equipe de assistência ao paciente.

\section{ABSTRACT}

Study aiming to identify the contribution provided by the application of alternative therapies in controlling anxiety in working professionals in a group by the children's onco-hematology, a city in the extreme south of Santa Catarina. The survey was of quali-quantitative approach, descriptive, exploratory and of field. The study was carried out with professional 09. Applied to anxiety rating scale of Hamilton in multidisciplinary team, alternative therapies and the semi-structured interview. The analysis of the qualitative data was carried out from the analysis of content. In quantitative data analysis phase of the evaluation scale of Anxiety of Hamilton, were 
quantified information through Microsoft Office Excel and presented by means of quantitative analysis. The result of the evaluation scale of Anxiety of Hamilton indicated that all the professionals presented anxiety, being $44.44 \%$ light level; $33.33 \%$ moderate level and $22.22 \%$ severe or intense level. After the application of alternative therapies, $28.57 \%$ of professionals who have moderate anxiety and $28.57 \%$ with intense anxiety migrated to take anxiety; $57.14 \%$ with significant reduction totaling the anxiety level. It is considered the effectiveness of use of alternative therapies for anxiety control of professionals and suggested the continuity of care of the caregiver as a way of improving the quality of life at work.

Descriptor: Anxiety; Quality of Life; Non-Governmental Organizations; Cancer Care Facilities; Patient Care Team. 


\section{INTRODUÇÃO}

Os profissionais de saúde vivenciam cotidianamente situações geradoras de ansiedade, sendo necessário que os gestores proporcionem melhores condições de trabalho, com atividades preventivas que evitem os transtornos mentais decorrentes das atividades laborais ${ }^{1}$. Lugarinho; Rosario ${ }^{2}$ reforçam que há a necessidade de implementação ou de ampliação de ações voltadas para o cuidar da saúde dos trabalhadores, principalmente da área de oncologia, pois as atividades do cotidiano no local de trabalho podem gerar tensões e produzir situações de alto grau de sofrimento, que levem o profissional ao adoecimento, quando não há o apoio adequado aos mesmos. Os cuidadores necessitam manter a integridade da sua própria saúde para terem condições de oferecer assistência qualificada aos pacientes e familiares ${ }^{2}$.

Santos; Pacheco ${ }^{3}$ abordam a especificidade do cuidado e da atenção à criança e ao adolescente com câncer. $O$ paradigma do cuidado com crianças e adolescentes com câncer se organiza em torno de um tripé: o paciente, sua família e a equipe de saúde. Crianças e adolescentes demandam uma dose intensa de afeto, sensibilidade e sinceridade na comunicação das difíceis notícias ao longo do tratamento.

Quanto à equipe, o desgaste físico e mental é intenso, assim como é alto o índice de estafa física e mental entre os profissionais de saúde. O trabalho na oncologia pediátrica evidencia, mais do que nunca, o reconhecimento das emoções como um instrumento valioso de trabalho. Abrir-se ao afeto que transborda nesses encontros com o sofrimento e a dor, compartilhando-os em um espaço de narratividade, resgata o profissional de saúde da solidão, permitindo-lhe elaborar melhor o luto e inquietação ${ }^{3}$.

No âmbito de saúde do trabalhador que atua na assistência oncológica, as questões do adoecimento adquirem relevância, pois a atividade de cuidar de pacientes com doença de alta complexidade demanda contato permanente com situações de dor, sofrimento e perdas. O estresse e ansiedade ocorrem pela sobrecarga física e emocional dos profissionais que desenvolvem atividades que os colocam na posição cotidiana de serem testemunhas e cuidadores do sofrimento alheio ${ }^{2}$. 
Os profissionais da saúde podem apresentar sintomatologia relacionada à ansiedade: cansaço, dor muscular, medo, insônia, depressão e estresse relacionado ao processo laboral. As terapias alternativas podem aliviar estes sintomas a partir de um cuidado holístico e integrador. Nessa perspectiva considera-se imprescindível o cuidado aos profissionais que atuam na oncologia, com a utilização das Práticas Integrativas e Complementares em saúde no controle da ansiedade, buscando uma melhor qualidade de vida no trabalho.

As práticas alternativas e complementares visam estimular o uso de métodos naturais de prevenção e recuperação, com ênfase no desenvolvimento do vínculo terapêutico, integração do ser humano com a natureza, visão ampliada do processo saúde-doença e a promoção do cuidado ${ }^{4-6}$.

De acordo com a Portaria o 971 de 3 de maio de 2006 as Práticas Integrativas e Complementares (PICs) são práticas que estimulam os mecanismos naturais de prevenção de agravos e recuperação de saúde e contribuem para a promoção da saúde, inserção social, redução de consumo de medicamentos, aumento da autoestima e melhoria da qualidade de vida-7.

Considera-se que as terapias alternativas podem promover à saúde física, mental e emocional dos profissionais da saúde, oportunizando o controle da ansiedade e consequentemente a melhoria da qualidade de vida no trabalho. Nesta perspectiva, esta pesquisa teve como objetivo identificar a contribuição proporcionada pela aplicação de terapia alternativa para o controle da ansiedade em profissionais atuantes em um grupo pela unidade infanto-juvenil de oncohematologia, de um município do Extremo Sul Catarinense.

\section{MÉTODO}

Trata-se de uma pesquisa de abordagem quali-quantitativa, descritiva, exploratória e de campo. $O$ estudo foi desenvolvido com 09 profissionais atuantes em um grupo pela unidade infanto-juvenil de onco-hematologia de um município do Extremo Sul de Santa Catarina, escolhidos através dos critérios de inclusão: equipe multiprofissional atuante na ONG; e aceitação para participar da Pesquisa segundo a Resolução 510/2016 ${ }^{8}$. 
Aplicou-se a Escala de Avaliação de Ansiedade de Hamilton na equipe multiprofissional da ONG, seguida das terapias alternativas e a entrevista semiestruturada para levantar o perfil da equipe, os fatores relacionados à ansiedade e a contribuição proporcionada pela aplicação de terapia alternativa para o controle da ansiedade.

\section{Entrevista semiestruturada com a Equipe multiprofissional}

A análise e interpretação dos dados qualitativos foi realizada pela categorização dos dados, através da ordenação, classificação e análise final dos dados pesquisados. Categoria refere-se a um conceito que abrange elementos ou aspectos com características comuns ou que se relacionam entre si, são estabelecidas para classificar os eventos. Categorizar é agrupar elementos, ideias ou expressões em torno de um conceito ${ }^{9,10}$.

\section{Escala de Ansiedade de Hamilton}

A Escala de Ansiedade de Hamilton ${ }^{11}$ compreende 14 itens distribuídos em dois grupos, sendo o primeiro grupo, com 7 itens, relacionado a sintomas de humor ansioso e o segundo grupo, também com 7 itens, relacionado a sintomas físicos de ansiedade - o que possibilita obter escores parciais, ou seja, separadamente para cada grupo de itens.

Segundo Bandeira ${ }^{12}$ dentre as escalas de humor utilizadas mundialmente e que foram traduzidas e adaptadas para a realidade brasileira para o quesito ansiedade, está a escala de Hamilton, que apresenta fácil aplicabilidade e confiabilidade._O escore total é obtido pela soma dos valores (graus) atribuídos em todos os 14 itens da escala, cujo resultado varia de 0 a 56. Os Graus de Ansiedade segundo Escala de Ansiedade de Hamilton são classificados em: nenhum = 0; leve = 1 ; médio $=2$; forte $=3$; máximo $=4^{12} \cdot$. A soma dos escores obtidos em cada item resulta em um escore total, que varia de 0 a 56 . Esse escore deve ser classificado de acordo com os intervalos: 0 (zero) caracteriza ausência de ansiedade; 1 a 17 
pontos caracterizam ansiedade leve; 18 a 24 pontos caracterizam ansiedade moderada; 25 a 56 pontos caracterizam ansiedade severa ou intensa ${ }^{12}$.

$\mathrm{Na}$ fase de análise de dados quantitativos da Escala de Avaliação de Ansiedade de Hamilton, as informações foram quantificadas através do Microsoft Office Excel e apresentados por meio de análise quantitativa.

Para preservar o sigilo decorrente das entrevistas realizadas, de acordo com as diretrizes e normas regulamentadoras da Resolução 510/2016 ${ }^{8}$, que envolve a pesquisa com Seres Humanos e Grupos Vulneráveis, utilizou-se a letra "P" para os profissionais da ONG; seguido do respectivo número - P1 a P9.

A pesquisa foi aprovada pelo Comitê de Ética em Pesquisa da UNESC pelo Projeto no $1.644 .500 / 2016$.

\section{RESULTADOS E DISCUSSÕES}

Em relação ao perfil dos profissionais entrevistados, dois são do sexo masculino e sete do sexo feminino; a faixa etária estabeleceu-se entre 28 à 56 anos; dentre eles, seis são casados e três solteiros; P1 é representante comercial e atua como cozinheira voluntária, P2 é psicóloga e atua na mesma área, P3 é formada em nutrição e atua no setor financeiro, P4 é publicitária e atua no marketing da ONG, P5 é bacharel em serviço social e atua como assistente social, P6 tem ensino fundamental completo e atua como mestre de obras, P7 é formada em pedagogia e artes visuais e atua como auxiliar administrativo, P8 é bacharel em ciências biológicas e atua como vice-presidente, e P9 é técnico em contabilidade e atua como presidente da ONG; o tempo de atuação dos profissionais na ONG variou de 1 mês e 15 dias à 8 anos.

Escala de Avaliação de Ansiedade de Hamilton

Após a seleção dos profissionais da ONG, a partir dos critérios de inclusão da pesquisa, realizou-se o teste de ansiedade de Hamilton. Todos os profissionais atuantes na ONG apresentaram ansiedade. 
Tabela 1 - Escala de avaliação de ansiedade de Hamilton dos Profissionais da ONG $(\mathrm{n}=09)$.

\begin{tabular}{lccc}
\hline Nível de Ansiedade & № & $\%$ & Profissionais (P1 A P9) \\
\hline Ausência de ansiedade & 0 & 0 & - \\
Ansiedade leve & 4 & $44,44 \%$ & P3, P4, P6, P7 \\
Ansiedade moderada & 3 & $33,33 \%$ & P2, P5, P9 \\
Ansiedade severa ou intensa & 2 & $22,22 \%$ & P1, P8 \\
Total & 9 & $100 \%$ & - \\
\hline
\end{tabular}

Fonte: dados da pesquisa, 2016.

Maronesi et $\mathrm{al}^{13}$ consideram a sobrecarga física e emocional um fator importante na geração de estresse em cuidadores, podendo afetar várias áreas da vida pessoal e familiar. A ansiedade e o estresse são sentimentos desagradáveis sendo encontrados em profissionais cuidadores, afetando sua vida profissional e familiar de forma negativa.

Realizou-se a entrevista semiestruturada com os profissionais da ONG organizando-se as categorias norteadoras da pesquisa antes da aplicação das Terapias Alternativas: Categoria 1 - Sintomas que denotam a ansiedade do profissional; Categoria 2 - Fatores relacionados à ocorrência da ansiedade. As categorias norteadoras da pesquisa após a aplicação das Terapias Alternativas foram às seguintes: Categoria 1 - Contribuição proporcionada pela aplicação de Terapia Alternativa para o controle da ansiedade; Categoria 2 - Sugestões frente à temática do Cuidado do Cuidador.

\section{Sintomas que denotam a ansiedade do profissional}

Em relação à sintomatologia que denota a ansiedade dos profissionais da ONG, 88,89\% relatou preocupações, previsão do pior, antecipação temerosa; $55,55 \%$ irritabilidade, nervosismo, agitação; dores de cabeça; dores nas costas; 44,44\% insônia e má digestão; 33,33\% dores musculares; dificuldade de concentração, falhas de memória; $22,22 \%$ tensão e dificuldade de relaxar; oscilação 
de humor; taquicardia, palpitações; 11,11\% medo; cansaço e fraqueza muscular; ranger de dentes; sensações auditivas de tinidos, zumbidos; falta de ar; roer unha, inquietação, movimentos motores excessivos e sudorese.

Tabela 2 - Sintomas relacionados à Ansiedade dos Profissionais da ONG $(\mathrm{n}=09)$

\begin{tabular}{|c|c|c|c|}
\hline Sintomas & № & $\%$ & Profissionais (P1 A P9) \\
\hline $\begin{array}{l}\text { Preocupações, previsão do } \\
\text { pior, antecipação temerosa }\end{array}$ & 8 & $88,89 \%$ & $\begin{array}{c}\text { P1, P3, P4, P5, P6, P7, P8, } \\
\text { P9 }\end{array}$ \\
\hline $\begin{array}{l}\text { Irritabilidade, nervosismo, } \\
\text { agitação }\end{array}$ & 5 & $55,55 \%$ & P1, P3, P4, P5, P7 \\
\hline Dores de cabeça & 5 & $55,55 \%$ & $\mathrm{P} 1, \mathrm{P} 2, \mathrm{P} 4, \mathrm{P} 5, \mathrm{P} 8$ \\
\hline Dores nas costas & 5 & $55,55 \%$ & $\mathrm{P} 1, \mathrm{P} 3, \mathrm{P} 5, \mathrm{P} 6, \mathrm{P} 8$ \\
\hline Insônia & 4 & $44,44 \%$ & P1, P4, P7, P8 \\
\hline Má digestão & 4 & $44,44 \%$ & $\mathrm{P} 1, \mathrm{P3}, \mathrm{P} 5, \mathrm{P} 9$ \\
\hline Dores musculares & 3 & $33,33 \%$ & P4, P6, P8 \\
\hline $\begin{array}{l}\text { Dificuldade de concentração, } \\
\text { falhas de memória }\end{array}$ & 3 & $33,33 \%$ & P1, P2, P6 \\
\hline $\begin{array}{l}\text { Tensão e dificuldade de } \\
\text { relaxar }\end{array}$ & 2 & $22,22 \%$ & P3, P4 \\
\hline Oscilação de humor & 2 & $22,22 \%$ & P1, P3 \\
\hline Taquicardia, palpitações & 2 & $22,22 \%$ & $\mathrm{P} 1, \mathrm{P} 4$ \\
\hline Medo & 1 & $11,11 \%$ & P3 \\
\hline $\begin{array}{l}\text { Cansaço e fraqueza } \\
\text { muscular }\end{array}$ & 1 & $11,11 \%$ & P6 \\
\hline Ranger de dentes & 1 & $11,11 \%$ & P4 \\
\hline $\begin{array}{l}\text { Sensações auditivas de } \\
\text { tinidos, zumbidos }\end{array}$ & 1 & $11,11 \%$ & P5 \\
\hline Falta de ar & 1 & $11,11 \%$ & P4 \\
\hline $\begin{array}{l}\text { Roer unha, inquietação, } \\
\text { movimentos motores } \\
\text { excessivos }\end{array}$ & 1 & $11,11 \%$ & P5 \\
\hline Outros: sudorese & 1 & $11,11 \%$ & P7 \\
\hline
\end{tabular}

Fonte: dados da pesquisa, 2016.

Os principais acometimentos relacionados com 0 desempenho ocupacional dos indivíduos adultos referem-se aos prejuízos apresentados em diferentes contextos como nos estudos, ambiente familiar, social e do trabalho. Nestes, são afetados aspectos que interferem destacando-se: alterações cognitivas, relacionadas principalmente com a memória, concentração e atenção; fadiga durante o dia; menor produtividade seja no trabalho ou nas atividades diárias de 
modo geral; absenteísmo, relacionado ao trabalho; relações familiares e sociais prejudicadas; distúrbios de humor e ansiedade ${ }^{14}$.

A preocupação e a ansiedade que podem ou não ser usadas como sinônimos fazem parte da vida de maneira natural. Porém, quando passam a ser constantes em graus mais elevados, não administrados e mal compreendidos, dá-se espaço para prejuízos diversos ${ }^{15}$.

Constata-se a variedade de sintomatologia relacionada à ansiedade apresentada pelos profissionais da ONG o que denota a importância de estratégias de prevenção visando o cuidado do cuidador.

\section{Fatores relacionados à ocorrência da ansiedade}

Em relação aos fatores relacionados a ocorrência da ansiedade organizaram-se as seguintes subcategorias: preocupações com a família e processo de trabalho; antecipação, não deixar nada para depois, personalidade; morte da criança.

Os profissionais relataram preocupações com a família e processo de trabalho, conforme os relatos:

P2 - "Às vezes o trabalho. Problemas pessoais são mais frequentes".

$P 4$ - "O trabalho, a vida amorosa. Sinto-me insegura. Tenho a sensação de muita coisa para fazer[...]".

$P 7$ - "Preocupação com os familiares, noticiários, em relação a vida profissional, e o falecimento das crianças da ONG".

P8 - "Preocupações do dia-a-dia, minha mente está sempre trabalhando, acordo às vezes na madrugada e começo a pensar na casa, nas crianças”.

$P 9$ - "Responsabilidades na instituição e na família gera preocupação e ansiedade. Zelo pelo trabalho".

Além de lidar com a dor do paciente, os profissionais da oncologia pediátrica têm seus afetos continuamente mobilizados pelas demandas feitas pelos familiares, sejam demandas de resolutividade técnica, sejam demandas de 
acolhimento da dor deles também, sendo que o processo de adoecimento da criança com câncer afeta toda a estrutura familiar².

A ansiedade caracteriza-se pela antecipação e previsão do pior, relacionada à precipitação e a inquietação, percebendo a necessidade de fazer tudo ao mesmo tempo, não conseguindo deixar as atividades para depois, o que depende da personalidade de cada indivíduo, conforme os relatos citados:

$P 1$ - "Eu gosto das coisas imediatas, não deixo nada para depois".

P3 - "Responsabilidades, comprometimento. Minha personalidade. Eu tento mudar, mas sempre volto a ser o que era antes".

P5 - "Ansiedade por antecipação decorrente de várias situações".

P6 - "Precipitação. Quero fazer as coisas tudo em um único dia. Sou muito afobado".

As perdas da vida no convívio familiar e na profissão são fatores relacionados à ocorrência da ansiedade na percepção dos profissionais P4 e P7:

$P 4$ - "O trabalho, a vida amorosa. Sinto-me insegura. Tenho a sensação de muita coisa para fazer. A perda da minha mãe ainda me afeta muito".

$P 7$ - "[...]o falecimento das crianças da ONG".

Para Teixeira Júnior, Sferra e Bottcher ${ }^{16}$ é justificado os indivíduos concederem à morte um caleidoscópio de significações. Os conflitos acarretados pela morte nos seres humanos, seja em relação à sua própria morte, à de seus familiares, ou mesmo no exercício profissional, deixam em relevo sentimentos diferentes exemplificados pela raiva, pela tristeza, pela barganha e pela negação, os quais carecem de discussão e de análise, de modo a propiciar um enfrentamento mais apropriado do processo de morte e morrer.

Os profissionais que atuam na oncologia lidam com um cotidiano de sofrimento, agravamento de doenças e frequente contato com a morte do paciente, estando envolvidos direta e constantemente com situações difíceis e sendo destinatários e porta-vozes de más notícias². 
O cuidado faz parte, portanto, da condição do humano. Cuidar do outro é cuidar de nós mesmos e podemos fazê-lo com criatividade ou não. Mas sem dúvida, a forma como cuidamos pode refletir o quanto nos permitimos chegar perto da consciência de que a morte está entrelaçada com a vida desde o nascimento. Viver é cuidar².

Aplicação das Práticas Alternativas nos Profissionais da ONG

Foram realizados 12 encontros de intervenção com aplicação de técnicas de alongamento, relaxamento, cromoterapia, musicoterapia, massoterapia, auriculoterapia e geoterapia. Cada encontro foi realizado em um período de tempo de 40 a 120 minutos, através de agendamento prévio e aceitação dos profissionais. Os encontros foram realizados em uma sala adaptada para as práticas, com ambiente privado e boa iluminação, na própria ONG pesquisada.

O maior número de encontros (12) foi destinado para a prática de auriculoterapia, onde cada profissional recebeu 07 aplicações. Nos demais encontros (03) foram realizados técnicas de relaxamento físico e mental associado à respiração profunda, musicoterapia e cromoterapia; aromaterapia; toque terapêutico e massoterapia; e geoterapia. As práticas alternativas foram aplicadas dependendo das situações de cada profissional. Aplicou-se a auriculoterapia conforme 0 diagnóstico dos pontos reagentes.

Nesta etapa participaram 07 profissionais da ONG (P1, P2, P3, P4, P5, P7, P8), ocorrendo 2 desistências (P6; P9).

\section{Relaxamento}

No preparo e harmonização do ambiente foi utilizado essência de lavanda e musicoterapia com música suave e relaxante e cromoterapia associada ao relaxamento físico mental. O relaxamento teve a duração de 1 hora com a participação de 04 profissionais da ONG (P2, P3, P4 e P7).

O relaxamento físico mental com a utilização de música e afirmações positivas podem reduzir a ativação do sistema nervoso central ${ }^{17}$. $\mathrm{O}$ uso da música 
nos processos saúde-doença-cuidado pode promover conforto e qualidade de vida para a pessoa adoecida ${ }^{18}$. A utilização de música nos cuidados paliativos é extremamente importante em virtude da contribuição multidimensional, sobretudo ao possibilitar um lugar de trocas - de afetos, de emoções, de delicadezas - que, por vezes, desaparece quando entra em cena a misteriosa e temida morte ${ }^{18}$.

O óleo de Lavanda (Lavandula officinalis) possui ação tranquilizante, equilibrante e calmante É indicado para tratar estresse, melancolia, depressão, debilidade, raiva, medo, ciúme, culpa, apatia, mudança de humor, confusão, timidez, divagação ${ }^{19}$.

Terapias de relaxamento utilizando imagens em vídeo, música e afirmações positivas podem reduzir a ativação do sistema nervoso central. $\mathrm{O}$ uso da música para relaxar vem sendo utilizado para redução da ansiedade, hostilidade, pressão arterial, dor, nervosismo e depressão ${ }^{17}$.

\section{Técnica de Auriculoterapia}

A aplicação da auriculoterapia foi realizada 1 vez por semana durante 12 semanas. Para o tratamento foram utilizados os seguintes materiais: apalpador; sementes de mostarda cor clara; placa Dux pequena para ponto semente; esparadrapo impermeável micropore (3M); pinça pequena; álcool 70\%; algodão.

Realizou-se a limpeza do pavilhão auricular com algodão e álcool $70 \%$, com a aplicação de sementes de mostarda previamente preparadas com esparadrapo para fixação nos pontos reagentes.

Os profissionais permaneceram com as sementes durante cinco dias, estimulando-as três vezes ao dia, depois retiraram as sementes no final do quinto dia.

A auriculoterapia é uma das técnicas empregadas pela Medicina Tradicional Chinesa, assim como acupuntura, massagem, entre outras técnicas, tendo como sua base definida em uma concepção de ser humano como ser integral, sem barreiras entre corpo, mente e espírito. Há vários benefícios, sendo os principais a diminuição do estresse e da ansiedade, além de ser uma aplicação rápida, simples, segura e pouco invasiva ${ }^{20}$. 
A seleção dos pontos foi realizada segundo o diagnóstico da auriculoterapia, baseado nos princípios da Medicina Tradicional Chinesa. Selecionou-se principalmente o ponto da ansiedade, coluna, coração, shenmen, rim e fígado.

O ponto shenmen (mente) - é a consciência organizadora, que se expressa no conjunto das funções do organismo, permitindo ao indivíduo comunicarse e se adaptar permanentemente ao que Ihe cerca. O psiquismo, a coerência de personalidade e aspectos mais elevados da inteligência são comandados pelo Shen ou mente. O ponto Shenmen tem relação direta com o meridiano do coração, pois é um ponto que controla a mente, tendo a função de acalmar e relaxar ${ }^{21}$.

Ponto rim - aos rins se atribuem não somente as funções de secreção, excreção e absorção dos rins da fisiologia ocidental, mas sua influência sobre as gônadas, a suprarrenal, a produção de medula óssea e características constitucionais hereditárias, o uso do ponto auricular dos rins como um ponto mobilizador de recursos energéticos e de reequilíbrio durante o processo vivenciado no estresse ${ }^{21}$. Fortalece a capacidade mental e emocional, indicado para medo e insegurança22.

Ponto do Fígado- tem ação calmante e elimina o calor local. É o ponto regulador do QI (energia) responsável por controlar a função dos músculos, além de fortalecer o baço. Com aplicação unilateral na orelha direita ${ }^{23}$.

O ponto coração tranquiliza e acalma a mente ${ }^{24}$. É a morada da mente e abriga todas as emoções, indicado nos casos de alterações emocionais, ansiedade; depressão, angústia, agitação mental e insônia ${ }^{22}$.

Ponto da Ansiedade: controla a ansiedade e a depressão ${ }^{22}$.

$O$ ponto tronco cerebral tem função sedativa, estimula e acalma a mente 21,24 .

Ponto da Coluna: analgesia e ação anti-inflamatória22.

Os pontos Shenmen e tronco cerebral têm propriedades calmantes, o ponto rim tem função energética e os pontos yang do fígado 1 e 2 têm a função de conter a subida de yang do fígado ${ }^{21}$. O Ponto Shenmen acalma a dor e a inflamação, acalma e relaxa a mente, ação sedativa e relaxante ${ }^{22}$. 
Os pontos ansiedade, tronco cerebral, coração, baço, fígado e Shenmen tem forte indicação para o transtorno de ansiedade ${ }^{24}$.

$\mathrm{Na}$ auriculoterapia, a ideia central é que toda parte do corpo tem um ponto reflexo correspondente na orelha, que pode ser utilizado para diagnóstico e tratamento. $O$ efeito positivo da auriculoterapia para redução dos níveis de estresse, está relacionado à diminuição da liberação do hormônio cortisol, que é um importante marcador dos níveis de estresse e tem um forte efeito anti-inflamatório ${ }^{21}$.

\section{Massoterapia com Toque Terapêutico}

A massoterapia com toque terapêutico foi realizada nas regiões da cabeça, mãos, pescoço e costas, com duração de 30 min cada. Utilizou-se um creme apropriado para a massagem e música relaxante em um ambiente harmonizado e preparado para a aplicação da técnica. As técnicas foram realizadas de acordo com as condições e aceitação do profissional e de forma individualizada. Participaram 5 profissionais (P2, P3, P4, P7 e P8).

A massagem é considerada um recurso terapêutico que contribui para $O$ alívio das dores físicas e emocionais, beneficiando todo o corpo e o sistema nervoso central e autônomo. Casos tidos na medicina tradicional como incuráveis recebem uma visão especial dentro da massoterapia que considera todos os aspectos do ser, principalmente $O$ aspecto energético. Todas as formas de toque estimulam os impulsos eletroquímicos da pele e seus inúmeros receptores. A massagem pode auxiliar na eliminação ou amenização de diverso estado mental, como: a depressão, ansiedade, angústia e a insônia ${ }^{25}$.

\section{Geoterapia}

No preparo da argila foi utilizado: argila (branca ou verde) e água filtrada em temperatura ambiente, formando um creme pastoso. Podem ser utilizados também água mineral, soro fisiológico, ou chá calmante, como a Camomila, em temperatura ambiente ou morna. A técnica foi realizada aplicando a argila verde em forma de compressa e a argila branca diretamente sobre a pele com o auxílio de um 
pincel. Cada aplicação durou por volta de 20 minutos, até a secagem da argila. A argila verde foi aplicada como compressa na cabeça para fins de alívio da dor no profissional P3. Participaram desta terapia os profissionais P3, P4 e P7.

A geoterapia é o uso terapêutico de $\operatorname{argilas}^{26,27}$. São definidas como materiais naturais terrosos que possuem em sua composição diferentes tipos de minerais: silicatos lamelares de magnésio e de alumínio, quartzo, feldspato, carbonatos, óxidos metálicos e cálcio ${ }^{27}$.

A utilização da argila no combate às doenças é um dos recursos mais antigos e tradicionais da humanidade. Seu efeito deve-se à capacidade da terra de reter energia proveniente da luz solar em seus cristais. A argila é capaz de retirar do organismo as energias perniciosas e de transferir energia vital para as áreas afetadas $^{26}$.

\section{Terapia Floral}

Os Florais foram indicados especificadamente para cada profissional de acordo com a sintomatologia apresentada na Escala de Ansiedade de Hamilton e nos resultados da entrevista semiestruturada, sendo utilizados durante um mês (setembro 2016). A forma de utilização do Floral foi 7 gotas $3 x$ ao dia, $25 \%$ brandy, sendo orientado para não deixar o Floral perto de celular, computador e eletroeletrônicos, além de guardá-lo em ambiente com temperatura amena, para evitar a desestabilização do produto e perda das propriedades terapêuticas.

As essências florais atuam nas desordens da personalidade, tendo como objetivo harmonizar o corpo etéreo, emocional e mental ${ }^{28}$.

O Floral de Bach Rescue Remedy da Inglaterra é indicado como floral do socorro, nas situações difíceis de sofrimento do corpo ou tormentos mentais, de traumas, para combater o medo, estresse e ansiedade, sendo uma combinação de 5 essenciais originais (Star Of Bethlehem, Rock Rose, Impatiens, Cherry Plum, Clematis) tornando-se uma essência única ${ }^{29}$.

Os Florais de Bach utilizados foram o Gentian para Depressão como consequência do Stress; White Chestnut para preocupação, tormento mental e insônia; Walnut indicado para promover constância e proteção energética; Larch 
para autoconfiança; Mimulus indicado para medo conhecido; Mustard para melancolia e oscilação de humor e Gorse para desesperança ${ }^{29-31}$.

Os Florais da Austrália compreenderam os florais Crowea para preocupação e stress; Black Eyed Susan indicado para organização mental e stress; Isopogan para memória; Dog Rose para o medo e insônia; Waratah para dar coragem, força e em estados depressivos; Macrocarpa para exaustão física e mental ${ }^{31}$.

Os Florais Californianos indicados foram Madia e Shasta Daisy para concentração e integração do pensamento de forma holística ${ }^{32,33}$.

A Terapia Floral evidencia os aspectos emocionais e não apenas os sintomas físicos. Os usuários da Terapia Floral relataram casos de curas e manifestaram-se sobre a resolutividade da terapêutica e humanização do cuidado. A terapêutica volta-se para o indivíduo no sentido de reparar-Ihe a energia vital ${ }^{22}$.

Comparativo da escala de avaliação de ansiedade de Hamilton antes e após a aplicação das Terapias Alternativas

Após a aplicação das terapias alternativas nos profissionais da ONG, realizou-se novamente o teste de ansiedade de Hamilton, onde $28,57 \%$ dos profissionais (P2, P5) identificados com ansiedade moderada e $28,57 \%$ com ansiedade intensa (P1, P8), migraram para ansiedade leve, totalizando $57,14 \%$.

Tabela 3 - Comparativo da Escala de Avaliação de ansiedade de Hamilton antes e após a aplicação das Terapias Alternativas $(n=07)$.

\begin{tabular}{|c|c|c|c|c|c|c|}
\hline \multirow[t]{2}{*}{$\begin{array}{l}\text { Nível de } \\
\text { Ansiedade }\end{array}$} & \multicolumn{2}{|c|}{$\begin{array}{c}\text { Antes da } \\
\text { utilização da } \\
\text { TA }\end{array}$} & \multirow[t]{2}{*}{$\begin{array}{l}\text { Profissionais } \\
\text { () }\end{array}$} & \multicolumn{2}{|c|}{$\begin{array}{c}\text { Após a } \\
\text { utilização da } \\
\text { TA }\end{array}$} & \multirow[t]{2}{*}{$\begin{array}{l}\text { Profissionais } \\
\text { (ㅁ) }\end{array}$} \\
\hline & № & $\%$ & & № & $\%$ & \\
\hline $\begin{array}{l}\text { Ausência de } \\
\text { ansiedade }\end{array}$ & 0 & 0 & & 0 & 0 & \\
\hline $\begin{array}{l}\text { Ansiedade } \\
\text { leve }\end{array}$ & 3 & $42,86 \%$ & P3, P4, P7 & 7 & $100 \%$ & $\begin{array}{c}\mathrm{P} 1, \mathrm{P} 2, \mathrm{P} 3, \mathrm{P} 4, \\
\text { P5, P7, P8 }\end{array}$ \\
\hline $\begin{array}{l}\text { Ansiedade } \\
\text { moderada }\end{array}$ & 2 & $28,57 \%$ & P2, P5 & 0 & 0 & \\
\hline Ansiedade & 2 & $28,57 \%$ & P1, P8 & 0 & 0 & - \\
\hline
\end{tabular}

Revista Inova Saúde, Criciúma, vol. 7, n. 1, jul. 2018.

ISSN 2317-2460 
severa ou

intensa

Total $\quad 7 \quad 100 \%$

Fonte: Dados da pesquisa, 2016.

Todos os profissionais apresentaram melhora da ansiedade, caracterizando $100 \%$ dos profissionais com ansiedade leve. Houve desistência de dois profissionais (P6 e P9), que não puderam continuar as aplicações.

\section{Contribuição proporcionada pela aplicação de Terapia Alternativa para o controle da Ansiedade}

Em relação à contribuição proporcionada pela aplicação das terapias alternativas, elencaram-se as seguintes subcategorias: melhora da ansiedade, estresse, humor; melhora da dor; melhora da insônia e resultado positivo.

Os profissionais consideraram que a aplicação da auriculoterapia semanal obteve resultado positivo.

P2 - "Foi positivo, nunca havia feito auriculoterapia e achei positivo".

P3 - "Resultado positivo".

P7 - "Algo que nunca havia feito, foi legal fazer algo diferente. A gente vive um dia muito agitado, um dia é diferente do outro, muda muito, não tenho como comparar, são dias intensos, hoje estou bem, amanhã já acontece coisas não muito boas, o fato de eu não sentir mais dor em relação as primeiras aplicações, e como fizemos toda semana, é um sinal que surtiu efeito".

P8 - "Todos os sintomas amenizaram, atingiu de alguma forma os pontos aplicados".

De acordo com os profissionais P1, P5 e P7, houve melhora da dor.

P1- "Melhorou bastante [...] coluna, joelho, articulação que doía [...]".

P5 - "Melhorou [...] dor no estômago". 
P7 - "Algo que nunca havia feito, foi legal fazer algo diferente. [...] o fato de eu não sentir mais dor em relação as primeiras aplicações, e como fizemos toda semana, é um sinal que surtiu efeito".

Os profissionais relataram melhora em relação aos sintomas da ansiedade, estresse e mudança de humor, conforme relatos abaixo:

$P 1$ - "Melhorou bastante, todos os problemas de estresse, coluna, joelho, articulação que doía, mudança de humor, ansiedade também senti diferença".

P3 - "Resultado positivo, amenizando os sintomas da ansiedade".

A auriculoterapia tem tido grande aceitabilidade, é segura e eficaz para diferentes condições de desequilíbrio energético, tendo sido reconhecida por seus efeitos positivos em distúrbios físicos, psíquicos e mentais, tem alto valor preventivo e terapêutico ${ }^{20}$.

Os profissionais relataram melhora da insônia, conforme relatos abaixo:

P4 - "Melhorou a insônia, passava o dia estressada, porque passava noites em claro, após o meio dia não prestava mais, e o "bruxismo", não rangeu tanto os dentes mais".

P5 - "Melhorou insônia, estou mais disposta, azia, dor no estômago".

Na Medicina Tradicional Chinesa quando uma pessoa sofre de insônia, outros dois órgãos, além dos rins, estão fora de equilíbrio o coração e o fígado. Cada um destes dois órgãos abriga um aspecto específico do espírito. Se esses órgãos estão fora de equilíbrio, eles não serão capazes de abrigar o espírito corretamente, ou perturbação do Shen, podendo manifestar-se de várias maneiras, incluindo distúrbios de humor e palpitações, porém a insônia é um dos sintomas mais comuns, e podem ser tratados com auriculoterapia onde se obtém melhora na indução e na qualidade do sono ${ }^{34}$.

Para Lugarinho; Rosário² a noção de cuidado de si permite igualmente ressignificar a importância do cuidado ao profissional, autorizando-o a assumir uma 
posição subjetiva mais ativa em relação aos inúmeros dilemas que habitam seu cotidiano de trabalho e não apenas respondendo reativamente aos acontecimentos, resvalando para a rotina, para a norma.

\section{Sugestões frente à temática do Cuidado Do Cuidador}

Os profissionais afirmaram que consideram muito importante o cuidado ao cuidador para sua qualidade de vida, melhorando na oferta de cuidados e sugeriram que houvesse continuidade desse trabalho.

P1 - "O cuidado foi importante na nossa qualidade de vida, assim posso oferecer cuidado as pessoas que cuidamos".

$P 2$ - "É extremamente importante. Penso que deveria ser contínuo, acontecer a cada semestre ou $1 x$ por ano, mas fora do horário de trabalho".

$P 3$ - "Acho excelente esse cuidado ao cuidador, só estando bem para poder oferecer cuidado ao próximo".

P4 - "Sugiro continuar após as aplicações".

P5 - "Bom, porque ajuda a relaxar, sente-se mais animada, mais disposição, dormir melhor, reflete no dia a dia, esse cuidado".

P7 - "Isso é bom. As pessoas geralmente acham que a gente não precisa de cuidado, que somos máquinas, porque prestamos cuidados aos outros, mas não é verdade precisamos também porque somos de carne e osso".

$P 8$ - "Foi tudo tão bom, trouxeram medicação para gente, se esforçaram se adequaram ao nosso tempo, foram insistentes, e não desistiram de nos prestar esse cuidado independente das circunstâncias. Foi surpreendente".

O cuidador, por vezes, deixa de cuidar de si para atender às demandas de cuidado da criança e entende que o autocuidado pode ser mal interpretado pelas pessoas com quem convive ${ }^{35}$. Porém, abrir mão de si para cuidar do outro é algo que pode ser sustentado durante certo período, mas quando ultrapassa o limite, gera a frustração pela falta de tempo para atender às necessidades e interesses pessoais ${ }^{36}$. 
O cotidiano desses trabalhadores exige, além da competência técnica e operacional, condições psíquicas, para administrar de forma adequada, a sobrecarga emocional gerada em suas atividades ${ }^{2}$, sendo de responsabilidade profissional, social e ética dos profissionais de saúde subsidiar o cuidador, proporcionar instrumentos e orientar estratégias necessárias para a execução do cuidado ${ }^{35}$.

Lugarinho; Rosario ${ }^{2}$ e Sena et al $^{1}$ reforçam que é necessário que os gestores implementem ou ampliem ações voltadas para a prevenção e o cuidado da saúde desses trabalhadores, evitando transtornos e tensões geradoras de alto grau de sofrimento desnecessário e prejudicial que podem levar ao adoecimento dos profissionais. O cuidado de si envolve saber lidar com as tensões próprias do cotidiano da vida, mas também do ambiente de trabalho, criando estratégias para evitar a ansiedade ${ }^{37}$.

\section{CONCLUSÕES}

O resultado da Escala de Avaliação de Ansiedade de Hamilton indicou que todos os profissionais atuantes na ONG apresentaram ansiedade, sendo $44,44 \%$ nível leve; $33,33 \%$ nível moderado e $22,22 \%$ nível severo ou intenso.

Com relação a sintomatologia que denota a ansiedade dos profissionais da ONG, 88,89\% relataram preocupações, previsão do pior e antecipação temerosa; $55,55 \%$ relataram sintomas como irritabilidade, nervosismo, agitação; dores de cabeça e dores nas costas; 44,44\% apresentaram insônia e má digestão; 33,33\% referiram dores musculares; dificuldade de concentração e falhas de memória; 22,22\% relataram tensão e dificuldade de relaxar; oscilação de humor; taquicardia e palpitações; $11,11 \%$ apresentaram sintomas de medo; cansaço e fraqueza muscular; ranger de dentes; sensações auditivas de tinidos, zumbidos; falta de ar; roer unha, inquietação, movimentos motores excessivos e sudorese.

Os fatores relacionados à ocorrência da ansiedade citados pelos profissionais foram a preocupação com a família e processo de trabalho; antecipação, não deixar nada para depois, relacionada a personalidade; morte relacionada ao processo de trabalho e familiar. 
$\mathrm{Na}$ aplicação das terapias alternativas foram utilizadas técnicas de alongamento, relaxamento, cromoterapia, musicoterapia, massoterapia, auriculoterapia e geoterapia. Após a aplicação das terapias alternativas nos profissionais da ONG, 28,57\% dos profissionais com ansiedade moderada e $28,57 \%$ com ansiedade intensa migraram para ansiedade leve; totalizando $57,14 \%$ com diminuição expressiva do nível de ansiedade.

As contribuições da aplicação das terapias alternativas foram relacionadas à melhora da ansiedade, estresse, humor; diminuição da dor; melhora da insônia, proporcionando um resultado positivo.

Considera-se essencial o cuidado ao cuidador visando melhorar a qualidade de vida dos profissionais da ONG, para que eles possam proporcionar melhor cuidado na assistência aos pacientes oncológicos e aos familiares, pois o bem-estar e a saúde dos trabalhadores são condições essenciais para 0 desenvolvimento de suas atividades.

Sugere-se a continuidade do cuidado ao cuidador, e como estratégias desse cuidado, podem ser desenvolvidas atividades com técnicas de alongamento, relaxamento, musicoterapia, entre outras, que permitam ao profissional aliviar as energias negativas e desgastantes adquiridas no cotidiano de trabalho, que causam estresse e ansiedade.

Portanto, considera-se a eficácia significativa da utilização das terapias alternativas para o controle da ansiedade dos profissionais da ONG e sugere-se a continuidade do cuidado do cuidador como forma de melhorar sua qualidade de vida.

\section{REFERÊNCIAS}

1. Sena AFJ, Lemes AG, Nascimento VF, Rocha EM. Estresse e ansiedade em trabalhadores de enfermagem no âmbito hospitalar. J Nurs Health. 2015; 5(1): 2737.

2. Lugarinho LP, Rosario SE. Atenção ao Vínculo e Saúde do Trabalhador: um Bom Encontro. In: INCA. Instituto Nacional de Câncer. Coordenação Geral de Gestão Assistencial. Coordenação de Educação. Comunicação de notícias difíceis: compartilhando desafios na atenção à saúde. Rio de Janeiro: INCA, 2010. p.37-45. 
3. Santos ADLM, Pacheco APAM. Há Saúde na Doença? - a Especificidade do Cuidado à Criança e ao Adolescente com Câncer. In: INCA. Instituto Nacional de Câncer. Coordenação Geral de Gestão Assistencial. Coordenação de Educação. Comunicação de notícias difíceis: compartilhando desafios na atenção à saúde. Rio de Janeiro: INCA, 2010. p.115-122.

4. Brasil. Ministério da Saúde. Secretaria de Atenção à Saúde. Departamento de atenção básica. Política Nacional de Práticas Integrativas e Complementares no SUS - PNIPIC - SUS. Brasília: Ministério da Saúde, 2008. 92 p.

5. Brasil. Ministério da Saúde. Secretaria de Atenção à Saúde. Departamento de Atenção Básica. Práticas integrativas e complementares: plantas medicinais e fitoterapia na Atenção Básica. Brasília: Ministério da Saúde, 2012. 156 p.

6. Brasil. Ministério da Saúde. Secretaria de Vigilância em Saúde. Secretaria de Atenção à Saúde. Política Nacional de Promoção da Saúde: PNPS: revisão da Portaria MS/GM no 687, de 30 de março de 2006. Brasília: Ministério da Saúde, 2015. 36 p.

7. Brasil. Ministério da Saúde. Portaria no 971, de 3 de maio de 2006. Política Nacional de Práticas Integrativas e Complementares (PNPIC) no Sistema Único de Saúde. acesso em 2016 out. 30]. Disponível em:

portal.saude.gov.br/portal/arquivos/pdf/PNPIC.pdf.

8. Brasil. Conselho Nacional de Saúde. Resolução no 510, de 07 de abril de 2016. [acesso em 2016 out. 30]. Disponível em:

http://conselho.saude.gov.br/resolucoes/2016/Reso510.pdf.

9. Leopardi MT. Metodologia da Pesquisa na Saúde. Florianópolis: UFSC, 2002.

10. Minayo MCS. Pesquisa social: teoria, método e criatividade. 28 ed. Petrópolis, RJ: Vozes, 2009. 108 p.

11. Hamilton M. The assesment of anxiety states by rating. BrJ Med Psych,1959.

12. Bandeira RA. Dor pós-operatória em idosos submetidos à prostatectomia transvesical: correlação com a ansiedade no pré-operatório. [Dissertação].[Brasília]: Universidade Católica de Brasília, 2010. 83 p. 
13. Maronesi LC, Silva NR, Cantu SO, Santos AR. Indicadores de estresse e sobrecarga em cuidadores formais e informais de pacientes oncológicos. Estud. pesqui. Psicol., Rio de Janeiro, 2014 dez.; 14(3):877-892.

14. Kubota AMA, Silva MNRMO, Masioli AB. Aspectos da insônia no adulto e a relação com o desempenho ocupacional. Rev. Ter. Ocup. Univ., São Paulo, 2014; 25(2):119-125.

15. Menezes EM. Ansiedade e/ou preocupação no contexto da liderança espiritual. Rev.Batista Pioneira. 2012; 1(1):07-21.

16. Teixeira Júnior MABT, Sferra LFB, Bottcher LB. A importância do lazer para a qualidade de vida do trabalhador. Rev. Conexão Elect. 2012; 9(1-2):1-15.

17. Primo CC, Amorim MHC, Leite FMC. A intervenção de enfermagem: relaxamento e seus efeitos no sistema imunológico de puérperas. Acta paul. enferm., São Paulo, 2011; 24(6): 751-755.

18. Seki NH, Galheigo SM. O uso da música nos cuidados paliativos: humanizando o cuidado e facilitando o adeus. Interface (Botucatu), Botucatu, 2010 jun.; 14(33):273284.

19. Gnatta JR, Dornellas EV, Silva MJP. O uso da aromaterapia no alívio da ansiedade. Acta paul. enferm., São Paulo, 2011; 24(2):257-63.

20. Kurebayashi LFS, Gnatta JR, Borges TP, Belisse G, Coca S, Minami A et al. Aplicabilidade da auriculoterapia com agulhas ou sementes para diminuição de estresse em profissionais de enfermagem. Rev.Esc.Enferm.USP, São Paulo, 2012; 46(1):89-95.

21. Kurebayashi LFS, Gnatta JR, Borges TP, Silva MJP. Avaliação diagnóstica da Medicina Tradicional Chinesa dos sintomas de estresse tratados pela auriculoterapia: ensaio clínico. Rev. Eletr. Enf. 2014 jan/mar;16(1):68-76.

22. Neves ML. Manual Prático de Auriculoterapia. $2^{\underline{a}}$ ed. Porto Alegre: Merithus, 2010. $100 \mathrm{p}$.

23. Araújo APS, Zampar R Pinto SME. Auriculoterapia no tratamento de indivíduos acometidos por distúrbios osteomusculares relacionados ao trabalho (DORT) / lesões por esforços repetitivos (LER). Arq. Ciênc. Saúde Unipar, Umuarama, 2006 jan./abr.; 10(1):35-42. 
24. Silvério-Lopes S, Seroiska MA. Auriculoterapia para Analgesia. Curitiba, PR: Omnipax, 2013.

25. Seubert $F$, Veronese L. A massagem terapêutica auxiliando na prevenção e tratamento das doenças físicas e psicológicas. In: Encontro Paranaense, Congresso Brasileiro, Convenção Brasil/Latino-América, XIII, VIII, II, 2008. Anais. Curitiba: Centro Reichiano, 2008.

26. Bontempo M. Manual da Medicina Integral. SP: Best Seller, 1998. 574 p.

27. Arthur K, Nascimento LC, Figueiredo DAS, Souza LB, Alfieri FM. Efeitos da geoterapia e fitoterapia associadas à cinesioterapia na osteoartrite de joelho: estudo randomizado duplo cego. Acta Fisiátr. 2012; 19(1):11-15.

28. Salles LF, Silva MJP. Efeito das essências florais em indivíduos ansiosos. Acta paul. enferm., São Paulo, 2012; 25(2):238-242.

29. Monari C. Participando da Vida com os Florais de Bach. SP: Roca, 2009.

30. Bach E. Os doze curadores e outros remédios. Inglaterra: The Bach Centre, 2014. $46 \mathrm{p}$.

31. Lambert E. Manual de Terapia Floral de Bach e da Austrália. São Paulo: Pensamento, 2011.

32. Kaminski P, Katz R. Repertório das essências florais: um guia abrangente das essências florais norte-americanas e inglesas, para o bem-estar emocional e espiritual. 2.ed. São Paulo: Triom, 2003. 369 p.

33. Stern C. Remédios Florais da Califórnia. São Paulo: Pensamento, 2004. 229 p.

34. Lisboa ARF. Acupuntura no tratamento da insônia: uma revisão. Monografia [Especialização].[ São José dos Campos ]: Faculdade de Educação, Ciência e Tecnologia - Unisaúde; 2014. 57 p.

35. Nascimento JD, Lacerda MR, Girardon-Perlini NMO, Camargo TB, Gomes IM, Zatoni DCP. A vivência do cuidado familiar em casas transitórias de apoio. Rev. Bras. Enferm., Brasília, 2016 jun.; 69(3):538-545.

36. Montefusco SRA, Bachion MM, Vera I, Caixeta C, Munari DB. Tensão do papel de cuidador: ocorrência em familiares de pessoas com doenças crônicas hospitalizadas. Ciência, Cuidado e Saúde. 2011; 10(4):828-835. 
Artigo Original

Atenção à Saúde

37. Ferreira ES, Souza MB, Souza NVDO, Tavares KFA, Pires AS. A relevância do cuidado de si para profissionais de enfermagem. Rev. Ciência, Cuidado e Saúde, Maringá - PR, 2015 jan/mar.; 14(1):978-985. 